\title{
THE INFLUENCES OF TRANSACTION COST FACTORS AND CAPABILITIES FACTORS ON THE DEGREE OF CHANNEL INTEGRATION
}

\author{
Hidesuke Takata, Keio University, Japan
}

\begin{abstract}
Over the past 25 years, transaction cost theory has emerged as one of the dominant theoretical perspectives to explain the forward vertical integration into distribution channels by manufacturers (e.g., Anderson, 1985; Anderson and Coughlan, 1987; Klein, Frazier, and Roth, 1990; Majumdar and Ramaswamy, 1994; Shervani, Frazier, and Challagalla, 2007). According to transaction cost theory (Williamson, 1985), it is argued that, as the degrees of specific assets in distribution functions and behavioral uncertainties by distributors increase, manufacturers will be more likely to use integrated channels. Most empirical tests show that this argument is supported (cf. Rindfleisch and Heide, 1997; Carter and Hodgson, 2006).
\end{abstract}

At the same time, several unanswered questions remain in transaction cost analyses. Intriguing questions include the relative effects of transaction costs and production costs on transaction governance, the impact of environmental uncertainty on governance decisions, the effects of communication mode on transaction costs and governance, and the influence of capabilities on the degree of vertical integration (cf. Rindfleisch and Heide, 1997; Rindfleisch et al., 2010). In such situations, this study sought to examine the influences of transaction costs and capabilities in determining the degree of channel integration. This question is considered to be important.

Currently, capabilities theory has emerged as a complementary approach to transaction cost theory. Also, growing numbers of scholars have recognized that a firm's capabilities, as well as transaction costs, can influence the degree of vertical integration (Langlois and Foss, 1999; Rindfleisch et al., 2010; Teece, 2010).

The hypotheses provided in this study are as follows. These are the ones that applied the respective major hypotheses of transaction cost theory (Williamson, 1975, 1985, 1986, 1991, 1999) and capabilities theory (Foss, 1993, 1996; Langlois and Robertson, 1995; Langlois and Foss, 1999; Langlois, 2004, 2007, 2009) to the issue of channel integration.

Transaction Cost Hypotheses

$\mathrm{H}_{1}$ : The greater the specificity of physical assets in distribution functions, the greater is the degree of channel integration.

$\mathrm{H}_{2}$ : The greater the specificity of human assets in distribution functions, the greater is the degree of channel integration.

$\mathrm{H}_{3}$ : The greater the difficulty in evaluating performance in distribution functions, the greater is the degree of channel integration.

Capabilities Hypotheses

$\mathrm{H}_{4}$ : The greater the technical complexity of product knowledge needed to perform distribution activities, the greater is the degree of channel integration.

$\mathrm{H}_{5}$ : The greater the interdependency between production and distribution activities, the greater is the degree of channel integration.

$\mathrm{H}_{6}$ : The greater the thickness of distribution markets, the lesser is the degree of channel integration.

Data necessary to test these hypotheses were gathered from Japanese manufacturers. Mail questionnaires were sent to 2393 sales divisions of manufacturers. In total, 294 divisions responded; of the responses, 273 provided usable data. The one dependent and six independent variables were measured by scales composed of items derived from prior research and items developed based on this study. The reliability and validity of the scales were examined, and good measurement properties were seen. The hypotheses were tested using two complementary approaches: structural equation model and hierarchical regression analyses.

First, the result of the structural equation model analysis is as follows. The model fitted the data well. The specificity of physical assets in distribution functions, specificity of human assets in distribution functions, technical complexity of product knowledge needed to perform distribution activities, interdependency between production and distribution activities, and thickness of distribution markets all had significant effects on the degree of channel integration. However, the difficulty in evaluating performance in distribution functions was unrelated to channel integration. Second, the result of the hierarchical regression analysis mirrored that of the structural equation model analysis.

References available upon request 